\title{
Rhizarthrosis: diagnostic assessment of rhizarthrosis and clinical-radiological correlation
}

\begin{abstract}
Objective: To evaluate diagnostic tests described for rhizarthrosis, to determine its sensitivity, specificity and accuracy, and to try to establish correlations between clinical and radiological conditions.
\end{abstract}

Method: This is a prospective study carried out at a university hospital, in the city of Campinas, Brazil. Patients were divided into 2 groups, Group A was evaluated according to the following data: age, sex, laterality of the pathology, dominant hand, length of symptoms, diagnostic tests (Grind Test, Digit-Pressure Test, Shear Test, 1st Metacarpal Flexion test, and 1st Metacarpal Extension Test), pain, radiological evaluation, and upper extremity functional index through the Quick DASH method. Group B (control group - with the same number of patients) was evaluated using the same methodology as Group A according to age, sex, diagnostic tests, and radiological evaluation.

Results: Group A- 34 patients were evaluated, 30 of whom were female (88.2\%), with a mean age of 60.6 years. Regarding the radiological classification, 3\% were Eaton type $1,38 \%$ type $2,56 \%$ type 3 , and $3 \%$, type 4 . The mildest group (Eaton type 1 and 2 ) represented $41.2 \%$ of the patients, and the more severe group (type 3 or 4 ) represented $58.8 \%$.There was statistical significance for the diagnosis of rhizarthrosis with the DigitPressure test $(p<0.001)$, Digit-Pressure test/Shear test $(p<0.001)$, Metacarpal Extension test $(p<0.001)$, Digit-Pressure/Metacarpal Extension tests $(p<0.001)$, Grind Test/Digit-Pressure test $(p<0.001)$, and Shear Test $(p=0.001)$. The Shear test/Metacarpal Extension test had the highest specificity, with $85.7 \%$. The Grind Test/Digit-pressure test had the highest accuracy, with $70.6 \%$ and the Digit-pressure test had the highest sensitivity, with $100 \%$. When all the tests were analyzed, individually and in pairs, there was greater specificity in digit-pressure test $(85.1 \%)$; sensitivity in digit-pressure test $(95.2 \%)$ and greater accuracy in digit-pressure test $(88.2 \%)$. There was statistical significance of the radiological classification with the Digit-Pressure test $(\mathrm{p}=0.030)$, and the Grind test/Digit-Pressure test combination $(\mathrm{p}=0.026)$ with Eaton and Littler stages 3 and 4.

Conclusion: The Digit Pressure Test, Digit Pressure test/Shear test, Shear Test, Metacarpal Extension test, Digit Pressure test/Metacarpal Extension test, and Grind Test/Digit Pressure test are significant for the diagnosis of rhizarthrosis. The clinical-radiological correlation of the Digit-Pressure Test with Eaton and Littler stages 3 and 4 is significant.
Volume 5 Issue 4 - 2020

\author{
Samuel Ribak, ${ }^{1,2}$ Eduardo Daniel Ferreira, ${ }^{1,2}$ \\ Helton Hiroshi Hirata,' Eduardo Lavor \\ Segura,' Rafael Barcellos de Campos,' \\ Alexandre Tietzmann' \\ 'Hand Surgery Service, Pontifical Catholic University of \\ Campinas, Campinas, Brazil \\ ${ }^{2}$ Orthopedics Service, Hospital Nossa Senhora do Pari, São
} Paulo, Brazil

Correspondence: Samuel Ribak, MD, PhD, Pontifícia Universidade Católica de Campinas (PUC-Campinas) Rua General Fernando Vasconcelos C Albuquerque (SP), CEP: 067II- 020, Brazil,Tel 0055। 000949198

Email ribaksamuel@yahoo.com.br

Received: July 08, 2020 | Published: July 232020

\section{Introduction}

The thumb constitutes $50 \%$ of hand function, thanks to the human race characteristic, the carpometacarpal joint (CMC, or trapeziometacarpal joint). This joint is distinct because it has great mobility, and is a saddle joint, thus presenting the disadvantage of having few restraints and being subject to greater stress. It is considered an unstable joint, increasing the risk of trapeziometacarpal joint pathologies. ${ }^{1}$

Thumb osteoarthritis in the trapeziometacarpal joint (rhizarthrosis) is one of the most common symptomatic conditions of the hand. ${ }^{2}$ It has a radiographic prevalence of $90 \%$ in patients over 80 years of age. ${ }^{3}$ It is present in $10 \%$ of the population between 45 and 48 years, affecting mainly women between the 5th and 6th decades of life, and $25 \%$ of post-menopausal women. ${ }^{2,3}$ It affects 6 to $12 \%$ of the adult population in Brazil, and is more prevalent in postmenopausal women., 4

The prevalence of rhizarthrosis is significant, affecting up to $10 \%$ of middle-aged women. Postmortem studies have identified rhizarthrosis in $75 \%$ of cases. ${ }^{6}$ Since it is a pathology with high incidence, such characteristics require a correct and early diagnosis.
The diagnosis of rhizarthrosis is based initially on the qualitative assessment of the history, where attention is focused on the location, duration, onset, frequency, intensity and quality of pain. Physical examination with the addition of special tests is important; later, complementary tests, such as hand X-rays, can be performed, if necessary.

Patients with painful CMC joint symptoms shall have a differential diagnosis for other pathologies, such as scaphoid fracture, flexor carpi radialis tendinitis, De Quervain's tenosynovitis, carpal instability, synovial cyst, and synovitis. ${ }^{8}$ Therefore, diagnostic tests are important for differential diagnosis.

To determine which diagnostic tests are the best, the ability to evaluate evidence describing the accuracy and interpretation of the results of each test is required. ${ }^{9}$

The best tests cited in the literature are: Grind Test, the digitpressure of the trapeziometacarpal joint, the shear test, the first metacarpal flexion test, and the first metacarpal extension test.

Grind Test is perhaps the best known and used test for the 
diagnosis of rhizarthrosis, as it is a specific test; however, due to its low sensitivity, ${ }^{10,11}$ the use of other tests that can lead to a more accurate diagnosis is often required. ${ }^{11,12}$

Hands radiographs are tests that complement the diagnosis of rhizarthrosis, bringing more information, including the joint condition in relation to the degree of arthrosis.

The fact that there is no direct correlation between the level of joint involvement and the patient's clinical condition ${ }^{13-15}$ is classical in the literature. It would be interesting to identify any correlation between the radiological types and the specific diagnostic tests to better assess the pathology.

The objective of this study is to evaluate diagnostic tests described for rhizarthrosis, to determine their sensitivity, specificity, and accuracy, and try to establish correlations between the clinical and radiological conditions.

\section{Material and methods}

This is a prospective study conducted between April 2018 and August 2019. The study was carried out at a university hospital, in the city of Campinas, São Paulo Brazil. The study was approved by the Ethics Committee, was submitted to Plataforma Brasil and all patients signed an Informed Consent Form.

The patients in this study were divided into 2 groups:

\section{Group A}

Patients with pain in the trapeziometacarpal joint and diagnosis of rhizarthrosis confirmed by the patient's history and imaging tests were included.

Those with concomitant upper limb pathologies were excluded, as well as those diagnosed with rhizarthrosis and already undergoing surgical treatment, and those who did not sign the informed consent form.

\section{Group B}

This group, called control group, included patients who visited the outpatient clinic due to complaints other than rhizarthrosis symptoms.

Those with concomitant upper limb pathologies were excluded, as well as the patients diagnosed with rhizarthrosis and already undergoing surgical treatment, and those who did not sign the informed consent form.

Group A patients were evaluated according to the following data:

Age; Sex; Laterality; Dominant hand; Length of symptoms.

Regarding the physical examination, all diagnostic tests were performed in a sequence, described below, and with an interval of 2 minutes between one test and the other for the manipulation of the previous test not to cause any change in the test performed later:

Grind Test (Figure 1): The examination is performed by moving the first metacarpal in a circle on the trapezium. In the first part of the test, in axial traction, and in the second time, in axial compression. The test is considered positive when the patient reports pain in the trapeziometacarpal region in the second part of the test. ${ }^{16-18}$

Digit-Pressure of the trapeziometacarpal joint (Figure 2): A firm palpation is performed on the back of the trapeziometacarpal joint. The test is considered positive when the patient reports pain in the trapeziometacarpal region.

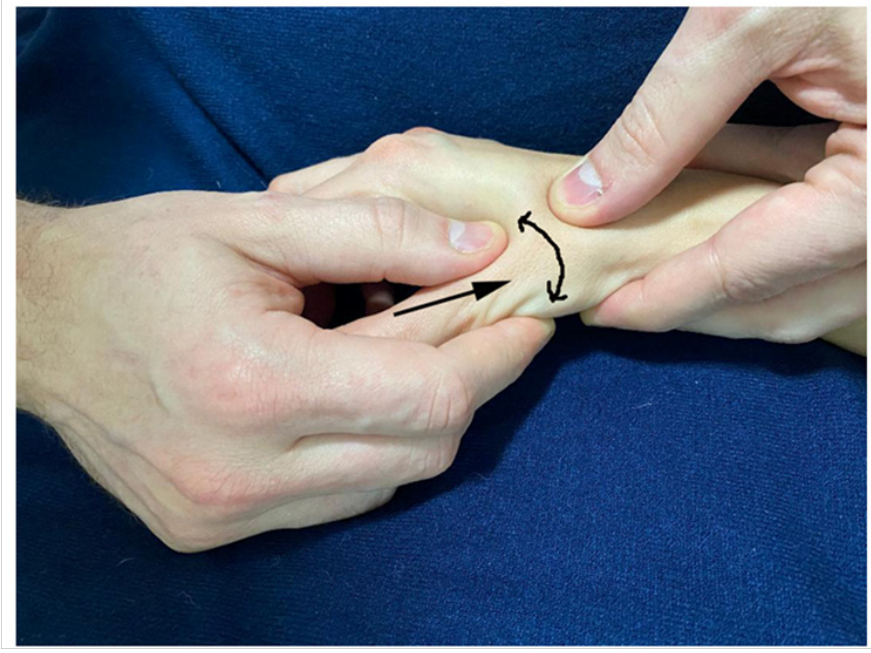

Figure I Grind test (right arrow shows axial compression of the trapeziometacarpal joint at second time, curved line with arrow shows moving the first metacarpal in a circle).

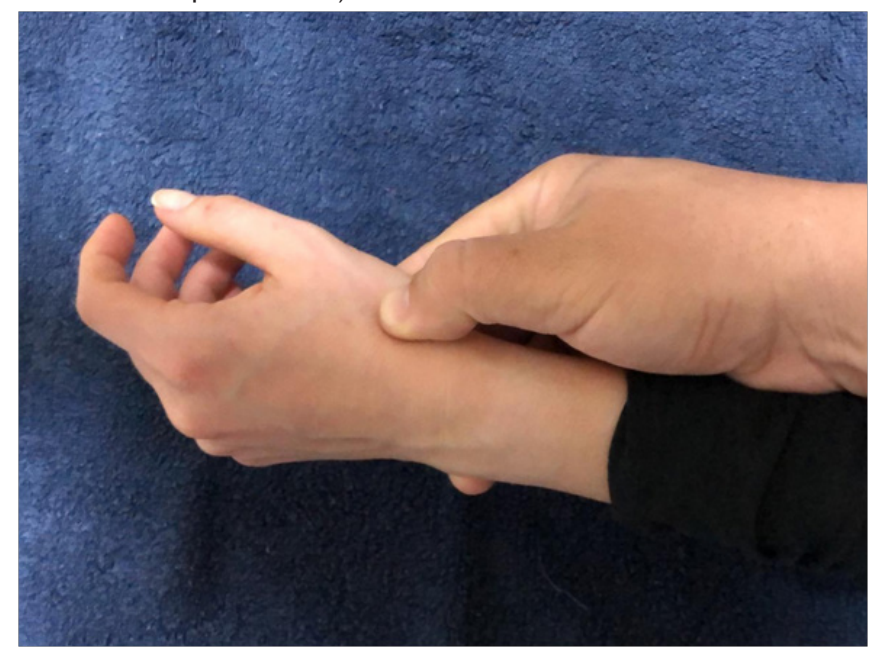

Figure 2 Digit-Pressure of the trapeziometacarpal joint (firm palpation is performed on the trapeziometacarpal joint).

Shear test (Figure 3): The trapezium is stabilized with one hand, and the base of the first metacarpal is supported with the other hand. Then, the thumb is pressed in the medial and lateral direction. The test is considered positive when the patient reports pain in the trapeziometacarpal region.

1st metacarpal flexion test (Figure 4): The examiner stabilizes the patient's wrist, metacarpals, and fingers with one hand and, with the other, flexion of the first metacarpal is performed. The test is considered positive when the patient reports pain in the trapeziometacarpal region.

1st metacarpal extension test (Figure 5): The examiner stabilizes the patient's wrist, metacarpals, and fingers with one hand and, with the other, extension of the first metacarpal is performed. The test is considered positive when the patient reports pain in the trapeziometacarpal region. 


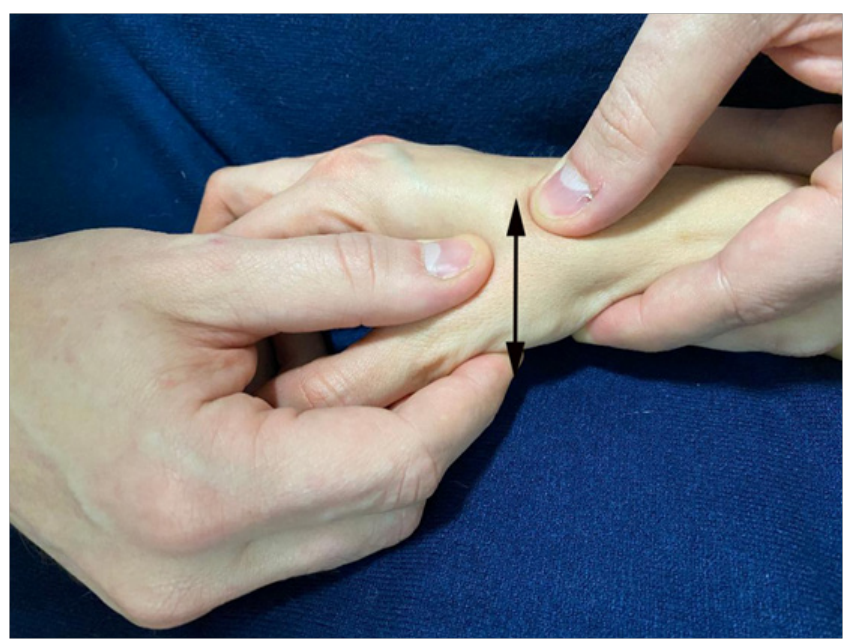

Figure 3 Shear test (double arrow shows the movement to the medial and lateral direction of I st metacarpal basis).

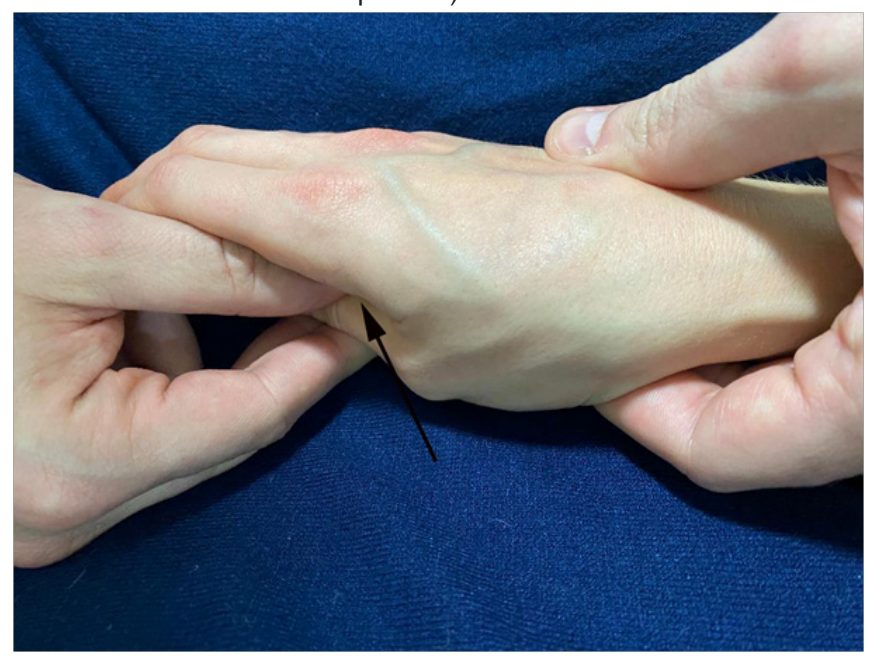

Figure 4 Ist metacarpal flexion test (right arrow shows Ist metacarpal flexion).

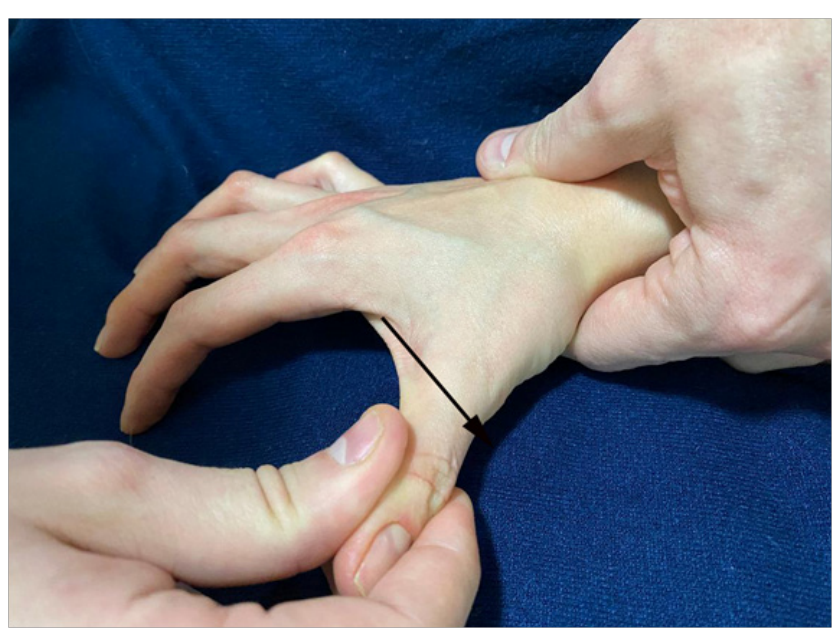

Figure 5 Ist metacarpal extension test (right arrow shows Ist metacarpal extension).
Trapeziometacarpal joint pain: It is evaluated at rest, during light and heavy activities

Patients were evaluated for the function of the upper limbs using the QuickDASH method.

QuickDASH consists of 11 original items from the DASH questionnaire on symptoms and skills to perform daily living tasks during the week prior to application. Each item has five answer options and the scores for all items are used to calculate the score on the scale (Table 1). The scores for symptoms and dysfunction in QuickDASH $=[($ sum of responses $/ \mathrm{n})-1] \times 25$, where $\mathrm{n}$ is the complete number of responses. The QuickDASH score cannot be calculated if there is more than one invalid item.

\section{Radiological evaluation}

All patients underwent hand X-rays in the lateral and Roberts (Flexion and internal rotation of the shoulder, hyperpronation of the thumb with the back in contact with the film) views, to assess the degree of arthrosis of the trapeziometacarpal joint, which was classified according to Eaton and Littler. ${ }^{19}$

Stage I: Normal joint or slight enlargement due to synovitis;

Stage II: Joint narrowing with free bodies and/or formation of 2-mm or smaller osteophytes;

Stage III: Joint narrowing with geodes, sclerosis, and formation of osteophytes larger than $2 \mathrm{~mm}$, with varying degrees of subluxation;

Stage IV: Stage III pathology with involvement of the scaphotrapezoid joint.

To evaluate the results, the group of milder cases, such as Eaton type 1 and 2, and the more severe types 3 or 4 cases were considered.

All data collected were recorded on the patient's general assessment form (Table 2).

Group B (control) patients were evaluated with the same methodology as Group A, regarding age, sex, diagnostic tests, and radiological evaluation, to identify trapeziometacarpal joint involvement.

To evaluate the results, and following statistical methodology, the following combinations of the various parameters collected were performed.

\section{Group A}

Combination analysis of all physical examination tests, individually, in pairs, and all together.

Combination Analysis of the radiological classification with mean age and QuickDASH.

Combination Analysis of the radiological classification with all physical examination tests, individually and in pairs.

\section{Group B}

Analysis of Group B together with Group A, to determine the sensitivity, specificity, and accuracy of each diagnostic test, individually and in pairs.

Sensitivity is understood as the ability of the diagnostic test to detect truly positive individuals, that is, to correctly diagnose the affected patients. 
Table I QuickDASH Questionnaire

\begin{tabular}{|c|c|c|c|c|c|}
\hline & $\begin{array}{l}\text { There was no } \\
\text { difficulty }\end{array}$ & $\begin{array}{l}\text { There was } \\
\text { less difficulty }\end{array}$ & $\begin{array}{l}\text { There was } \\
\text { moderate } \\
\text { difficulty }\end{array}$ & $\begin{array}{l}\text { There was } \\
\text { moderate } \\
\text { difficulty }\end{array}$ & $\begin{array}{l}\text { Couldn't } \\
\text { accomplish }\end{array}$ \\
\hline I.To open a new or very tight jar lid & I & 2 & 3 & 4 & 5 \\
\hline $\begin{array}{l}\text { 2. To do heavy domestic chores (e.g., wash walls, wash } \\
\text { the floor) }\end{array}$ & 1 & 2 & 3 & 4 & 5 \\
\hline 3. To carry a bag or a small suitcase. & I & 2 & 3 & 4 & 5 \\
\hline 4. To wash your own back. & I & 2 & 3 & 4 & 5 \\
\hline 5. To use a knife to cut food. & I & 2 & 3 & 4 & 5 \\
\hline $\begin{array}{l}\text { 6. Recreational activities requiring some strength or } \\
\text { impact on your arms, shoulders or hands (e.g., to play } \\
\text { volleyball, to hammer) }\end{array}$ & 1 & 2 & 3 & 4 & 5 \\
\hline \multirow{3}{*}{$\begin{array}{l}\text { 7. Last week, at what extent did your problem in the } \\
\text { arm, shoulder or hand affect your normal activities } \\
\text { with your family, friends, neighbors, or peers? }\end{array}$} & Did not affect & $\begin{array}{l}\text { Affected a } \\
\text { little }\end{array}$ & $\begin{array}{l}\text { Affected } \\
\text { moderately }\end{array}$ & Affected a lot & $\begin{array}{l}\text { Affected in an } \\
\text { extreme way }\end{array}$ \\
\hline & 1 & 2 & 3 & 4 & 5 \\
\hline & Did not limit & Limited a little & $\begin{array}{l}\text { Limited } \\
\text { moderately }\end{array}$ & Limited a lot & Couldn't do it \\
\hline $\begin{array}{l}\text { 8. Last week, were your work or other regular daily } \\
\text { activities limited due to your problem on the arm, } \\
\text { shoulder, or hand? }\end{array}$ & I & 2 & 3 & 4 & 5 \\
\hline \multicolumn{6}{|c|}{ Please, measure the severity of the following symptoms in the previous week. (Circle the number) } \\
\hline & None & Little & Moderate & Severe & Extreme \\
\hline 9. Pain on your arm, shoulder, or hand & I & 2 & 3 & 4 & 5 \\
\hline \multirow{2}{*}{$\begin{array}{l}\text { 10. Discomfort on the skin (prickling) on your arm, } \\
\text { shoulder, or hand. }\end{array}$} & I & 2 & 3 & 4 & 5 \\
\hline & $\begin{array}{l}\text { There was no } \\
\text { difficulty }\end{array}$ & Little difficulty & $\begin{array}{l}\text { Moderate } \\
\text { difficulty }\end{array}$ & Severe difficulty & $\begin{array}{l}\text { So hard that I } \\
\text { couldn't sleep }\end{array}$ \\
\hline $\begin{array}{l}\text { II. Last week, how much difficulty did you have to } \\
\text { sleep because of the pain on your arm, shoulder, or } \\
\text { hand? (circle the number) }\end{array}$ & I & 2 & 3 & 4 & 5 \\
\hline
\end{tabular}

Please measure your ability to accomplish the following activities in the previous week circling the appropriate number for your answer

Table 2 General assessment form containing all items researched for data collection to be used in the study

\begin{tabular}{|c|c|c|c|c|c|}
\hline \multicolumn{6}{|l|}{ I.Age } \\
\hline 2. Sex & Female & Male & & & \\
\hline 3. Laterality & Right & Left & & & \\
\hline 4. Dominant hand & Right & Left & & & \\
\hline 5. Length & $<6$ months & 6 months to I year & 1 year to 2 years & $>2$ years & \\
\hline 6. Tests & Grind test & Cmc digit-pressure & Shear & Mtc flexion & Mtc extension \\
\hline 7. $X$ ray (eaton) & Grade I & Grade 2 & Grade 3 & Grade 4 & \\
\hline 8. Pain & At rest & Light activity & Heavy activity & & \\
\hline
\end{tabular}


Table 3 Tests Positivity Rate

\begin{tabular}{|c|c|c|c|c|c|}
\hline & \multicolumn{2}{|c|}{ Negative } & \multicolumn{2}{|c|}{ Positive } & \multirow[t]{2}{*}{ P-value } \\
\hline & $\mathbf{N}$ & $\%$ & $\mathbf{N}$ & $\%$ & \\
\hline Grind & 10 & $29.40 \%$ & 24 & $70.60 \%$ & $<0.001$ \\
\hline Digit-pressure & 3 & $8.80 \%$ & 31 & $91.20 \%$ & $<0.001$ \\
\hline Shear & 8 & $23.50 \%$ & 26 & $76.50 \%$ & $<0.001$ \\
\hline MTC Flexion & 20 & $58.80 \%$ & 14 & $41.20 \%$ & 0.146 \\
\hline MTC Extension & 8 & $23.50 \%$ & 26 & $76.50 \%$ & $<0.001$ \\
\hline Grind / Digit & 12 & $35.30 \%$ & 22 & $64.70 \%$ & 0.015 \\
\hline Grind / Shear & 15 & $44.10 \%$ & 19 & $55.90 \%$ & 0.332 \\
\hline Grind / Flexion & 23 & $67.60 \%$ & II & $32.40 \%$ & 0.004 \\
\hline Grind / Extension & 14 & $41.20 \%$ & 20 & $58.80 \%$ & 0.146 \\
\hline Digit / Shear & 10 & $29.40 \%$ & 24 & $70.60 \%$ & $<0.001$ \\
\hline Digit / Flexion & 20 & $58.80 \%$ & 14 & $41.20 \%$ & 0.146 \\
\hline Digit / Extension & II & $32.40 \%$ & 23 & $67.60 \%$ & 0.004 \\
\hline Shear / Flexion & 22 & $64.70 \%$ & 12 & $35.30 \%$ & 0.015 \\
\hline Shear / Extension & 25 & $73.50 \%$ & 9 & $26.50 \%$ & $<0.001$ \\
\hline Flexion / Extension & 23 & $67.60 \%$ & II & $32.40 \%$ & 0.004 \\
\hline General Test & 16 & $47.10 \%$ & 18 & $52.90 \%$ & 0.628 \\
\hline
\end{tabular}

Specificity is understood as the ability of the diagnostic test to detect truly negative individuals, that is, to correctly diagnose healthy individuals.

Accuracy is understood as the degree to which the test or an estimate based on a test is able to determine the true value of what is being measured, that is, it informs whether the results represent the "truth" or how far they are from the truth.

\section{Statistical analysis}

For the results of the statistical analysis, a significance level of $0.05(5 \%)$ was defined. Parametric statistical tests were used to test the normality of quantitative variables.

The tests used were:

Student's t Test, Chi-Square Test, Equality of Two Proportions Test, Sensitivity and Specificity, Confidence Interval for the Mean, P-value, and Kolmogorov-Smirnov Test.

\section{Results}

\section{Group A}

Thirty-four patients were evaluated, of whom 30 were female (88.2\%), with ages ranging from 36 to 80 years (mean of 60.6 years) and predominance of the left side.

Regarding the upper extremity functional index (QuickDASH), the value varied between 0 and 90.9 points, with an average of 42.77 points.

Regarding the radiological classification, 3\% were Eaton type 1, $38 \%$ type $2,56 \%$ type 3 , and $3 \%$, type 4 . The mildest group (Eaton type 1 and 2 ) represented $41.2 \%$ of the patients, and the more severe group (type 3 or 4 ) represented $58.8 \%$.

Analyzing the tests individually, a positive index was obtained, in decreasing order of:

$$
\begin{aligned}
& \text { 91.2\% for the Digit-pressure test; } \\
& 76.5 \% \text { for the shear test; } \\
& 76.5 \% \text { for the Metacarpal Extension test; } \\
& 70.6 \% \text { for the Grind Test; } \\
& 41.2 \% \text { for the metacarpal flexion test. }
\end{aligned}
$$

The tests considered statistically significant, individually, were: Grind Test $(p<0.001)$; Digit-pressure test $(p<0.001)$; Shear test $(p<0.001)$, and Metacarpal extension test $(p<0.001)$. The only nonsignificant test was the Metacarpal Flexion test (Table 3).

When the tests were combined, the ones considered significant were: Digit-pressure test/Shear test $(\mathrm{p}<0.001)$; Shear test/metacarpal extension test $(p<0.001)$; Grind Test/Metacarpal flexion test $(p=0.004)$; Digit-pressure/Metacarpal extension tests $(\mathrm{p}=0.004)$; metacarpal flexion/metacarpal extension tests $(\mathrm{p}=0.004)$; Grind Test/Digitpressure test $(\mathrm{p}=0.015)$; Shear test/Metacarpal flexion test $(\mathrm{p}=0.015)$. Those where no statistical significance was found were: Grind Test/ Shear test; Grind Test/Metacarpal extension test; Digit-pressure test/ metacarpal flexion test, and General Test (Table 3).

When the combination of the results of the radiological classification and age was analyzed, no statistical significance was found.

When the combination of the results of the radiological classification and QuickDASH was analyzed, no statistical significance was found.

When the combination of the results of the radiological classification with the individual tests was analyzed, the Digit-pressure test showed to be significant, with $100 \%$ sensitivity (Table 4).

In patients classified as Eaton 3 and 4, there was a 100\% positive correlation with the Digit-pressure test. In patients Eaton 1 and 2, there was a $78.6 \%$ positive correlation (Table 4 ).

The combination of the results of the radiological classification with the combined tests showed statistical significance only with the Grind Test/Digit-pressure test (Table 4).

In patients classified as Eaton 3 and 4, there was an $80 \%$ positive correlation with the Grind Test/Digit-pressure test. In patients Eaton 1 and 2 , there was a $78.6 \%$ positive correlation (Table 4 ).

The Shear test/Metacarpal Extension test had the highest specificity, with $85.7 \%$ (Table 5). The Grind Test/Digit-pressure test had the highest accuracy, with $70.6 \%$ (Table 5). The Digit-pressure test had the highest sensitivity, with $100 \%$ (Table 5).

\section{Group B}

When adding the Control Group (Group B) to Group A, to determine the sensitivity, specificity, and accuracy in the diagnosis of rhizarthrosis, the tests individually considered statistically significant were: Digit-pressure test $(\mathrm{p}<0.001)$; Metacarpal extension test $(\mathrm{p}<0.001)$; Shear test $(\mathrm{p}<0.001)$, Grind Test $(\mathrm{p}<0.006)$. The only nonsignificant test was the Metacarpal Flexion test (Table 6). In group B, the same number of patients in group A was evaluated, 34. 
Table 4 Combination of clinical and radiological pictures

\begin{tabular}{|c|c|c|c|c|c|c|c|c|}
\hline & & \multicolumn{2}{|c|}{ Eaton 3/4 } & \multicolumn{2}{|c|}{ Eaton $1 / 2$} & \multicolumn{2}{|c|}{ Total } & \multirow[t]{2}{*}{ P-value } \\
\hline & & $\mathbf{N}$ & $\%$ & $\mathbf{N}$ & $\%$ & $\mathbf{N}$ & $\%$ & \\
\hline \multirow[t]{2}{*}{ Grind } & Positive & 16 & $80.00 \%$ & 8 & $57.10 \%$ & 24 & $70.60 \%$ & 0.15 \\
\hline & Negative & 4 & $20.00 \%$ & 6 & $42.90 \%$ & 10 & $29.40 \%$ & \\
\hline \multirow[t]{2}{*}{ Digit-pressure } & Positive & 20 & $100 \%$ & 11 & $78.60 \%$ & 31 & $91.20 \%$ & 0.03 \\
\hline & Negative & 0 & $0.00 \%$ & 3 & $21.40 \%$ & 3 & $8.80 \%$ & \\
\hline \multirow[t]{2}{*}{ Shear } & Positive & 15 & $75.00 \%$ & 11 & $78.60 \%$ & 26 & $76.50 \%$ & 0.809 \\
\hline & Negative & 5 & $25.00 \%$ & 3 & $21.40 \%$ & 8 & $23.50 \%$ & \\
\hline \multirow[t]{2}{*}{ MTC flexion } & Positive & 9 & $45.00 \%$ & 5 & $35.70 \%$ & 14 & $41.20 \%$ & 0.588 \\
\hline & Negative & 11 & $55.00 \%$ & 9 & $64.30 \%$ & 20 & $58.80 \%$ & \\
\hline \multirow[t]{2}{*}{ MTC extension } & Positive & 15 & $75.00 \%$ & 11 & $78.60 \%$ & 26 & $76.50 \%$ & 0.809 \\
\hline & Negative & 5 & $25.00 \%$ & 3 & $21.40 \%$ & 8 & $23.50 \%$ & \\
\hline \multirow[t]{2}{*}{ Grind/Digit } & Positive & 16 & $80.00 \%$ & 6 & $42.90 \%$ & 22 & $64.70 \%$ & 0.026 \\
\hline & Negative & 4 & $20.00 \%$ & 8 & $57.10 \%$ & 12 & $35.30 \%$ & \\
\hline \multirow[t]{2}{*}{ Grind/Shear } & Positive & 11 & $55.00 \%$ & 8 & $57.10 \%$ & 19 & $55.90 \%$ & 0.901 \\
\hline & Negative & 9 & $45.00 \%$ & 6 & $42.90 \%$ & 15 & $44.10 \%$ & \\
\hline \multirow[t]{2}{*}{ Grind/Flexion } & Positive & 8 & $40.00 \%$ & 3 & $21.40 \%$ & 11 & $32.40 \%$ & 0.255 \\
\hline & Negative & 12 & $60.00 \%$ & 11 & $78.60 \%$ & 23 & $67.60 \%$ & \\
\hline \multirow[t]{2}{*}{ Grind/Extension } & Positive & 13 & $65.00 \%$ & 7 & $50.00 \%$ & 20 & $58.80 \%$ & 0.382 \\
\hline & Negative & 7 & $35.00 \%$ & 7 & $50.00 \%$ & 14 & $41.20 \%$ & \\
\hline \multirow[t]{2}{*}{ Digit/Shear } & Positive & 15 & $75.00 \%$ & 9 & $64.30 \%$ & 24 & $70.60 \%$ & 0.5 \\
\hline & Negative & 5 & $25.00 \%$ & 5 & $35.70 \%$ & 10 & $29.40 \%$ & \\
\hline \multirow[t]{2}{*}{ Digit/Flexion } & Positive & 9 & $45.00 \%$ & 5 & $35.70 \%$ & 14 & $41.20 \%$ & 0.588 \\
\hline & Negative & 11 & $55.00 \%$ & 9 & $64.30 \%$ & 20 & $58.80 \%$ & \\
\hline \multirow[t]{2}{*}{ Digit/Extension } & Positive & 15 & $75.00 \%$ & 8 & $57.10 \%$ & 23 & $67.60 \%$ & 0.273 \\
\hline & Negative & 5 & $25.00 \%$ & 6 & $42.90 \%$ & 11 & $32.40 \%$ & \\
\hline \multirow[t]{2}{*}{ Shear/Flexion } & Positive & 8 & $40.00 \%$ & 4 & $28.60 \%$ & 12 & $35.30 \%$ & 0.493 \\
\hline & Negative & 12 & $60.00 \%$ & 10 & $71.40 \%$ & 22 & $64.70 \%$ & \\
\hline \multirow[t]{2}{*}{ Shear/Extension } & Positive & 7 & $35.00 \%$ & 2 & $14.30 \%$ & 9 & $26.50 \%$ & 0.178 \\
\hline & Negative & 13 & $65.00 \%$ & 12 & $85.70 \%$ & 25 & $73.50 \%$ & \\
\hline \multirow[t]{2}{*}{ Flexion/Extension } & Positive & 8 & $40.00 \%$ & 3 & $21.40 \%$ & 11 & $32.40 \%$ & 0.255 \\
\hline & Negative & 12 & $60.00 \%$ & 11 & $78.60 \%$ & 23 & $67.60 \%$ & \\
\hline \multirow[t]{2}{*}{ General Test } & Positive & 12 & $60.00 \%$ & 6 & $42.90 \%$ & 18 & $52.90 \%$ & 0.324 \\
\hline & Negative & 8 & $40.00 \%$ & 8 & $57.10 \%$ & 16 & $47.10 \%$ & \\
\hline
\end{tabular}


Table 5 Accuracy, sensitivity, specificity, positive and negative predictive value of tests

\begin{tabular}{llllll}
\hline & Statistics & & & & \\
& Accuracy & Sensitivity & Specificity & VP + & VP - \\
\hline Grind & $64.70 \%$ & $80.00 \%$ & $42.90 \%$ & $66.70 \%$ & $60.00 \%$ \\
Digit-pressure & $67.60 \%$ & $100 \%$ & $21.40 \%$ & $64.50 \%$ & $100.00 \%$ \\
Shear & $52.90 \%$ & $75.00 \%$ & $21.40 \%$ & $57.70 \%$ & $37.50 \%$ \\
MTC Flexion & $52.90 \%$ & $45.00 \%$ & $64.30 \%$ & $64.30 \%$ & $45.00 \%$ \\
MTC Extension & $52.90 \%$ & $75.00 \%$ & $21.40 \%$ & $57.70 \%$ & $37.50 \%$ \\
Grind / Digit & $70.60 \%$ & $80.00 \%$ & $57.10 \%$ & $72.70 \%$ & $66.70 \%$ \\
Grind / Shear & $50.00 \%$ & $55.00 \%$ & $42.90 \%$ & $57.90 \%$ & $40.00 \%$ \\
Grind / Flexion & $55.90 \%$ & $40.00 \%$ & $78.60 \%$ & $72.70 \%$ & $47.80 \%$ \\
Grind / Extension & $58.80 \%$ & $65.00 \%$ & $50.00 \%$ & $65.00 \%$ & $50.00 \%$ \\
Digit / Shear & $58.80 \%$ & $75.00 \%$ & $35.70 \%$ & $62.50 \%$ & $50.00 \%$ \\
Digit / Flexion & $52.90 \%$ & $45.00 \%$ & $64.30 \%$ & $64.30 \%$ & $45.00 \%$ \\
Digit / Extension & $61.80 \%$ & $75.00 \%$ & $42.90 \%$ & $65.20 \%$ & $54.50 \%$ \\
Shear / Flexion & $52.90 \%$ & $40.00 \%$ & $71.40 \%$ & $66.70 \%$ & $45.50 \%$ \\
Shear / Extension & $55.90 \%$ & $35.00 \%$ & $85.70 \%$ & $77.80 \%$ & $48.00 \%$ \\
Flexion / Extension & $55.90 \%$ & $40.00 \%$ & $78.60 \%$ & $72.70 \%$ & $47.80 \%$ \\
General Test & $58.80 \%$ & $60.00 \%$ & $57.10 \%$ & $66.70 \%$ & $50.00 \%$ \\
\hline
\end{tabular}

When the tests were combined, the ones considered significant were: Digit-pressure test/Shear test $(\mathrm{p}<0.001)$; Digit-pressure test/ Metacarpal extension test $(\mathrm{p}<0.001)$; Grind Test/Digit-pressure test $(\mathrm{p}<0.001)$; Shear test/Metacarpal extension test $(\mathrm{p}=0.001)$; Grind Test/Shear test $(p=0.003)$, Digit-pressure test/Metacarpal flexion test $(\mathrm{p}=0.003)$; Grind Test/Metacarpal extension test $(\mathrm{p}=0.007)$, and Shear test/ Metacarpal flexion test $(\mathrm{p}=0.024)$. The tests where no statistical significance was found were: Grind Test/Metacarpal flexion test, and Metacarpal flexion test/Metacarpal extension test (Table 6).

When the analysis of the tests was carried out individually, there was a better result with the Digit-pressure test, with sensitivity of $85.1 \%$, specificity of $95.2 \%$, and accuracy of $88.2 \%$, followed by the Metacarpal extension test, Shear test, and Grind Test (Table 6).

Table 6 Accuracy, sensitivity, and specificity in the diagnosis of rhizarthrosis

\begin{tabular}{|c|c|c|c|c|c|c|c|c|}
\hline $\mathbf{R X}$ & & With Disease & $\begin{array}{l}\text { Without } \\
\text { disease }\end{array}$ & Total & P-value & Accuracy & Sensitivity & Specificity \\
\hline \multirow[t]{2}{*}{ Grind } & Positive & 28 & 5 & 33 & 0.006 & $64.70 \%$ & $59.60 \%$ & $76.20 \%$ \\
\hline & Negative & 19 & 16 & 35 & & & & \\
\hline \multirow[t]{2}{*}{ Digit } & Positive & 40 & I & 41 & $<0.001$ & $88.20 \%$ & $85.10 \%$ & $95.20 \%$ \\
\hline & Negative & 7 & 20 & 27 & & & & \\
\hline \multirow[t]{2}{*}{ Shear } & Positive & 33 & 6 & 39 & 0.001 & $70.60 \%$ & $70.20 \%$ & $71.40 \%$ \\
\hline & Negative & 14 & 15 & 29 & & & & \\
\hline \multirow[t]{2}{*}{ Flexion } & Positive & 20 & 4 & 24 & 0.061 & $54.40 \%$ & $42.60 \%$ & $81.00 \%$ \\
\hline & Negative & 27 & 17 & 44 & & & & \\
\hline \multirow[t]{2}{*}{ Extension } & Positive & 30 & 3 & 33 & $<0.001$ & $70.60 \%$ & $63.80 \%$ & $85.70 \%$ \\
\hline & Negative & 17 & 18 & 35 & & & & \\
\hline \multirow[t]{2}{*}{ Grind/Digit } & Positive & 25 & I & 26 & $<0.001$ & $66.20 \%$ & $53.20 \%$ & $95.20 \%$ \\
\hline & Negative & 22 & 20 & 42 & & & & \\
\hline \multirow[t]{2}{*}{ Grind/Shear } & Positive & 22 & 2 & 24 & 0.003 & $60.30 \%$ & $46.80 \%$ & $90.50 \%$ \\
\hline & Negative & 25 & 19 & 44 & & & & \\
\hline
\end{tabular}




\begin{tabular}{|c|c|c|c|c|c|c|c|c|}
\hline $\mathbf{R X}$ & & With Disease & $\begin{array}{l}\text { Without } \\
\text { disease }\end{array}$ & Total & P-value & Accuracy & Sensitivity & Specificity \\
\hline \multirow[t]{2}{*}{ Grind/Flexion } & Positive & 15 & 4 & 19 & 0.275 & $47.10 \%$ & $31.90 \%$ & $81.00 \%$ \\
\hline & Negative & 32 & 17 & 49 & & & & \\
\hline \multirow[t]{2}{*}{ Grind/Extension } & Positive & 23 & 3 & 26 & 0.007 & $60.30 \%$ & $48.90 \%$ & $85.70 \%$ \\
\hline & Negative & 24 & 18 & 42 & & & & \\
\hline \multirow[t]{2}{*}{ Digit/Shear } & Positive & 30 & I & 31 & $<0.001$ & $73.50 \%$ & $63.80 \%$ & $95.20 \%$ \\
\hline & Negative & 17 & 20 & 37 & & & & \\
\hline \multirow[t]{2}{*}{ Digit/Flexion } & Positive & 19 & I & 20 & 0.003 & $57.40 \%$ & $40.40 \%$ & $95.20 \%$ \\
\hline & Negative & 28 & 20 & 48 & & & & \\
\hline \multirow[t]{2}{*}{ Digit/Extension } & Positive & 26 & I & 27 & $<0.001$ & $67.60 \%$ & $55.30 \%$ & $95.20 \%$ \\
\hline & Negative & 21 & 20 & 41 & & & & \\
\hline \multirow[t]{2}{*}{ Shear/Flexion } & Positive & 17 & 2 & 19 & 0.024 & $52.90 \%$ & $36.20 \%$ & $90.50 \%$ \\
\hline & Negative & 30 & 19 & 49 & & & & \\
\hline \multirow[t]{2}{*}{ Shear/Extension } & Positive & 25 & 2 & 27 & 0.001 & $64.70 \%$ & $53.20 \%$ & $90.50 \%$ \\
\hline & Negative & 22 & 19 & $4 \mid$ & & & & \\
\hline \multirow[t]{2}{*}{ Flexion/Extension } & Positive & 15 & 3 & 18 & 0.128 & $48.50 \%$ & $31.90 \%$ & $85.70 \%$ \\
\hline & Negative & 32 & 18 & 50 & & & & \\
\hline
\end{tabular}

When the tests combination analysis was performed, the best result was with the combination of the Digit-pressure test/Shear test, with a sensitivity of $63.8 \%$, specificity of $95.2 \%$, and accuracy of $73.5 \%$, followed by the Digit-pressure test/Metacarpal extension test; Grind Test/Digit-pressure test; Shear test/ Metacarpal extension test; Grind Test/Shear test; Digit-pressure test/metacarpal flexion test; Grind Test/Metacarpal extension test, and Shear test/Metacarpal flexion test.

When all the tests were analyzed, individually and in pairs, there was greater specificity in: Digit-pressure test (85.1\%); Shear test (70.2\%); Digit-pressure test/ Shear test (63.8\%); Metacarpal extension test $(63.8 \%)$, and Grind Test $(59.6 \%)$.

When all tests were analyzed, individually and in pairs, there was greater sensitivity in: Digit-pressure test (95.2\%); Digit-pressure test/Shear test (95.2\%); Digit-pressure test/metacarpal extension test (95.2\%); Grind Test/Digit-pressure test (95.2\%), and Digit-pressure test/metacarpal flexion test (95.2\%).

When all tests were analyzed, individually and in pairs, there was greater accuracy in: Digit-pressure test $(88.2 \%)$; Digit-pressure test/ Shear test $(73.5 \%)$; Shear test $(70.6 \%)$; Metacarpal extension test (70.6\%), and Digit-pressure test/Metacarpal extension test (67.6\%).

\section{Discussion}

Patients with the diagnostic possibility of rhizarthrosis, which incidentally is a very common pathology, need to have the correct diagnosis and, consequently, receive the best treatment. Thus, the correlation of special tests is essential.

The Grind test is often cited as the main test, although there are limited data to support its prognostic value. There are even other tests; however, they are less mentioned and to have a diagnostic value they need to be compared, and thus, better defined as to their sensitivity, specificity and accuracy. ${ }^{10-12}$

Gelberman et al. ${ }^{10}$ report that thumb adduction and extension tests are more sensitive than the Grind Test, and their evaluation showed they are excellent. Due to its low sensitivity, the Grind Test is defined as a less useful diagnostic tool.

Merrit et al. ${ }^{11}$ on the contrary, believe that the positive Grind Test is useful to confirm the diagnosis of rhizarthrosis. They cite the negative Grind Test as useful in identifying people who do not have rhizarthrosis. In their work, both the sensitivity and the negative predictive value were only moderate, and a negative Grind Test did not necessarily reflect radiographic evidence of rhizarthrosis.

Choa et al. ${ }^{12}$ show the Shear test as more specific than the Grind test. They conclude that the Shear test has greater sensitivity (66.7\%) and specificity (100\%) than the Grind Test (30\% and $96.7 \%$, respectively), as well as a positive predictive value (100\%) and negative predictive value (75\%) higher than the Grind Test (90\% and 58\%, respectively). They prefer the Shear test and discard the Grind Test.

In general, the literature mentions articles that evaluate tests, but we did not find a work description evaluating all tests in the same study, as the authors of this study did.

The objective of this study was to obtain the value of five different diagnostic tests regarding their sensitivity, specificity, and accuracy. The intention was to compare the results of each test individually, and check their combination in pairs, as well as together. The relation between the Eaton-Littler radiological classification and all tests was also verified.

Our results showed a predominance of the Digit-pressure test and the combination of the Digit-pressure test/ Shear test. These tests are less cited in the literature, but they complement the results of studies that classically use the Grind Test.

Radiographs are important in the diagnosis of rhizarthrosis, but classically there is no association of the clinical picture and the severity of the pathology with the radiological picture. ${ }^{13-15}$

Regarding the attempt of clinical-radiological correlation, our study showed that the correlation between the Digit-pressure test and 
the combination of the Grind Test/Digit-pressure test with stages 3 and 4 of Eaton and Littler was significant, showing that, specifically in the positive cases for the Digit-pressure test and Grind Test/Digitpressure test, patients certainly have radiograph images showing greater severity.

Our results allow us to infer that for patients with suspected rhizarthrosis, the best tests to consider would be the Digit-pressure test followed by the combination of the Digit-pressure test/ Shear test, Shear Test, Metacarpal extension test, Digit- pressure test/ Metacarpal extension test, and Grind Test/Digit-pressure test.

\section{Conclusion}

The Digit-pressure test, Digit-pressure test/Shear test, Shear Test, Metacarpal extension test, Digit-pressure test/Metacarpal extension test, and Grind Test/Digit-pressure test are significant for the diagnosis of rhizarthrosis.

The clinical-radiological correlation of the Digit-pressure test with Eaton and Littler stages 3 and 4 is significant.

\section{Acknowledgements}

None.

\section{Conflict of interest}

No potential conflict of interest relevant to this article was reported.

\section{References}

1. Buckner WS. Terapia ocupacional: capacidades práticas para as disfunções físicas. Artrite. In: Pedretti LW, Early MB. editors. 5a ed. São Paulo: Roca; 2005;847-74.

2. Wolfe SW. et al. Green'S Operative Hand Surgery. 7th ed. Philadelphia, PA: Elsevier,2017;345-369.

3. Armstrong AL, Hunter JB, Davis TR. The prevalence of degenerative arthritis of the base of the thumb in postmenopausal women. $J$ Hand Surg Br. 1994;19:340-341.

4. Colditz J, Koekebakker N. A new splint design for the thumb CMC joint.

5. Carreira ACG, Jones A, Natour J. Assessment of the effectiveness of a functional splint for osteoarthritis of the trapeziometacarpal joint of the dominant hand: a randomized controlled study. $J$ Rehabil Med. 2010;42(5):469-474.
6. Parker WL. Evidence-based medicine: thumb carpometacarpal arthroplasty. Plast Reconstr Surg. 2013;132(6):1706-1719.

7. Patel TJ, Beredjiklian PK, Matzon JL. Trapeziometacarpal joint arthritis. Curr Rev Musculoskelet Med. 2013;6(1):1e8.

8. Eaton RG, Glickel SZ. Trapeziometacarpal osteoarthritis: staging as a rationale for treatment. Hand Clin. 1987;3:455-469.

9. Fritz JM, Wainner RS. Examining diagnostic tests: an evidence-based perspective. Phys Ther. 2001;81(9):1546e1564.

10. Gelberman RH, Boone S, Osei DA, et al. Trapeziometacarpal arthritis: a prospective clinical evaluation of the thumb adduction and extension provocative tests. J Hand Surg Am. 2015;40(7):1285e1291.

11. Merritt MM, Roddey TS, Costello C, et al. Diagnostic value of clinical grind test for carpometacarpal osteoarthritis of the thumb. $J$ Hand Ther. 2010;23(3): 261e267.

12. Choa RM, Parvizi N, Giele HP. A prospective case-control study to compare the sensitivity and the specificity of the grind and tractionshift (subluxationrelocation) clinical tests in osteoarthritis of the thumb carpometacarpal joint. J Hand Surg Eur. 2014;39(3):282e285.

13. Berger AJ, Momeni A, Ladd AL. Intra- and interobserver reliability of the Eaton classification for trapeziometacarpal arthritis: a systematic review. Clin Orthop Relat Res. 2014;472(4):1155e1159.

14. Kubik 3rd NJ, Lubahn JD. Intrarater and interrater reliability of the Eaton classification of basal joint arthritis. J Hand Surg Am. 2002;27(5):882e885.

15. Spaans AJ, van Laarhoven CM, Schuurman AH, et al. Interobserver agreement of the Eaton- Littler Classification system and treatment strategy of thumb carpometacarpal joint osteoarthritis. J Hand Surg Am. 2011;36(9):1467e1470.

16. Carr MM, Freiberg A. Osteoarthritis of the thumb: clinical aspects and management. Am Fam Physician. 1994;50:995e1000.

17. North ER, Eaton RG. Degenerative joint disease of the trapezium: a comparative radiographic and anatomic study. J Hand Surg Am. $1983 ; 8: 160 \mathrm{e} 167$.

18. Glickel SZ. Clinical assessment of the thumb trapeziometacarpal joint. Hand Clin. 2001;17:185e195.

19. Eaton RG, Lane LB, Littler JW. Ligament reconstruction for the painful thumb carpometacarpal joint: a long-term assessment. J Hand Surg Am. 1984;9(5):692-699. 